\title{
SNOW ACCUMULATION AND ABLATION
}

$T$ HE mass of snow and ice stored at high elevations on the Earth is a large reservoir of the hydrological cycle. Any reduction in its mass by melting releases potential energy, and the debts of past climates become discharged. We have neither made much use of this energy nor made a serious attempt to measure its size or its fluctuations. Even the mass of water accumulated in annual snowfields is measured only in a few places, and yet its sudden release in a thaw is often the source of a disastrous flood; for example, the 1950 Red River flood at Winnipeg. If the snow stored in the upper catchment area of the River Severn were known and the relation between its ablation and the weather were established, it would be possible to predict the likelihood and the size of the flood lower down the river. Unfortunately, however, snow accumulation and ablation are not easy to measure, and we have almost no knowledge of the quantity of water lying as snow in any catchment area in Britain.

The discussion meeting on "Snow Accumulation and Ablation", organized jointly by the Royal Meteorological Society and the British Glaciological Society and held in London on January 18, was concerned mainly with the problem as it affects the budget of glaciers. Even in Britain, glaciers are of interest; for as one speaker (L. C. W. Bonacina) romarked, there would be glaciers in Scotland after fifty summers--not winters-like that of 1951.

It is well known that European glaciers are retreating in association with the warming of the climate. Their retreat is measured in the simplest way by recording the annual change in the position of the glacier tongue. This measurement merely indicates that the glacier is striving to balance its income, the total accumulation, against its expenditure, the net ablation; but it reveals neither the sizes of its budgetary items, nor which climatic variable dominates its retreat. For that purpose it is necessary to measure the annual changes in the glacier mass both in the higher parts where there is a surplus (the net accumulation) and at the lower levels where there is a deficiency (the net ablation). This will show whether the retreat is associated with decreased precipitation or with increased atmospheric heat causing greater ablation. Then it is necessary to investigate the heat balance at the glacier surface to discover the importance of the various meteor. ological factors causing the ablation. All the heat sources and sinks at the glacier surface have to be measured: the not radiation, the convection from the air, the conduction from the glacier, the evapora. tion and the condensation. This task is similar to estimating the heat balance at the ground surface, with the one simplification that the snow surface remains at $0^{\circ} \mathrm{C}$. whenever melting occurs.

Such investigations of the mass and heat budget of a glacier are difficult undertakings, and it is not surprising that only a few studies have been made. The observations of Ahlmann and Eriksson in North East Land in 1931 were analysed by Angström ${ }^{1}$. An intensive study of the heat balance over a glacier surface was made by Sverdrup $2-4$, Ahlmann and Olsson on Isachsen's Plateau in Spitsbergen in 1934. Sverdrup's findings were used to obtain some idea of the relation between ablation and climate on the Vatnajökull in Iceland by Ahlmann and Thorarinsson ${ }^{5}$, and these findings were also applied to observations on the Fröya Glacier in East Greenland by Eriksson ${ }^{6}$. The most exhaustive study has been made by Wallén ${ }^{7}$ on the small, but accessible, Kårsa Glacier in Swedish Lapland. This is the only study that has covered a number of consecutive years (1942-48), and it was concluded that the principal cause of the recession of the glacier was increased ablation associated with increased summer temperature and humidity, and a longer ablation season. More recently, Baird ${ }^{8}$, Ward ${ }^{9}$ and Orvig ${ }^{10}$ have made the first studies in the Canadian Arctic on two ice caps in Baffin Island, and observations have been made on the ice shelf of Queen Maud Land in the Antarctic ${ }^{11}$. (An ice shelf is a coastwise glacier composed of land ice, sea ice and local snow, generally floating on the sea.)

The discussion at the meeting was opened by R. A. Hamilton, of the British North Greenland Expedition, who gave a brief description of the geography and glaciology of the Greenland ice cap and of its dominant weather systems.

H. Lister, another member of the Expedition, followed with a detailed account of his measurements of the ablation and of the heat balance during the melting season made on one of the glaciers flowing from the Greenland ice cap. The practical difficulties of using normal meteorological instruments to measure the gradients of temperature, vapour pressure and wind speed over a polar glacier surface were well illustrated. The many meteorologists present must have been convinced of the need for the development of more suitable instruments for reliable work in cold climates. The subject of heat transport through the air has been one of much controversy during recent years in the light of current ideas on turbulence, and thore is a feeling that the Greenland ice cap is not a convenient place to delve into detailed research on this problem; it can be pursued more profitably on the snowfields of the Cairngorms, for example. Such a site would be suitable also for development trials of instruments and for determining the optimum observations required for a study of heat balance. It is gratifying to record that P. D. Baird, of the University of Aberdeen, has made a start in this direction, with the help of the Meteorological Office, by establishing a weather station on the Cairngorm plateau this winter.

W. H. Ward spoke generally of the problems of the direct measurement of snow accumulation and ablation in the light of his experiences on two ice caps in Baffin Island, Canada. The long-term seasonal measurement of accumulation and ablation was not too difficult and was easiest in the ablation zone of a glacier. It was a question of measuring the change in the mass of water relative to a suitable reference horizon, and the dense ice surface in the ablation zone was a convenient reference. But in the thick permeable accumulation zone it was sometimes impracticable to reach a reference level through which some melt water did not seep and re-freeze at a lower level. When accumulation and ablation 
occurred intermittently, it was difficult to define the duration of the ablation season.

Daily measurements of ablation and accumulation are of greater interest to the meteorologist, and the usual methods of measurement are subject to many errors. The ablation is frequently measured by the lowering of the surface relative to a stake sunk in the snow, and the change in level is multiplied by a density to give the ablation in, say, inches of water. But the surface can settle for a variety of reasons. Compaction can occur without ablation, melt water descending through subsurface snow can cause compaction beneath a frozen snow surface and radiation can cause melting below the surface. Furthermore, the snow density varies irregularly with depth. Constant watching of the snow and the weather cannot eliminate all sources of error. In the accumulation area of a glacier during the melting season, the total mass of ice and water can be measured by sampling every snow layer from a pit dug to a suitable reference level. The density of each sample and the thickness of each layer are measured and their products summed up. That task may easily take a full day's work. The water content of all the samples can be measured by calorimetry, but it is an impossible task in a deep profile.

These are the methods of measurement available at present, and there is a pressing need to develop a simple field-method of recording separately the total masses of water and ice in a melting snow profile.

W. H. WARD

${ }^{1}$ Geog. Ann., 16, 264 (1933).

'Geog. Ann., 17, 145 (1935).

- Chr. Michelsens Inst. for Videnskap og Ådsfrihet. Beretningar, 5, 3 (1935).

'Geofis. Pub., 11, No. 7 (1936).

${ }^{5}$ Geog. Ann., 20, No. 3-4 (1938).

- Geog. Ann., 24, 23 (1942).

7 Geog. Ann., 30, 451 (1948).

8 J. Glaciol., 2, 2 (1952).

J. Glaciol., 2, 158 (1953).

10 Geog. Ann., 36, 193 (1954)

11 Weather, 7, 314 and 327 (1952).

\section{TESTING OF METALS BY OPTICAL METHODS}

$\mathrm{O}$ January 13 a symposium, at which there were some sixty participants, was held at the Institute of Physics, London, on "The Possible Uses of Surface Methods as a Means of Testing Metals (with Special Reference to Optical Methods)". This was sponsored by the Non-Destructive Testing Group of the Institute of Physics, and it was to be understood that only non-destructive methods were to be discussed. The symposium was opened by Prof. S. Tolansky, of the Royal Holloway College, University of London, Dr. O. S. Heavens, of the University of Reading, and Dr. R. W. B. Stephens, of the Imperial College of Science and Technology, University of London, who each in turn gave a half-hour discourse on selected topics, after which the meeting was thrown open to general discussion. The chair was occupied by Dr. J. Thewlis.

In an introductory survey, illustrated by some forty slides, Prof. Tolansky selected as typical subjects for examination some of his own studies on the optical testing of surface finish, of microtopography in general, the examination of micro-hardness and directional hardness, the character of electrodeposits and the examination of machined metal surfaces. Attention was devoted to five different methods of approach which he uses for the study of surface structure. There is first two-beam interferometry, which is capable of extensive application; then, for increased precision, indeed reaching down to structural features the heights of which approach crystal lattice dimensions, there is multiple-beam interferometry in a variety of forms, examples of which were shown. It was stressed that the great resolutions attainable are only in the height-depth dimension and not in extension across the surface. Experiments revealing the perfection of contour of the silver layers used in multiple-beam interferometry were described. The light-profile microscope was then illustrated, and it was emphasized that this has very obvious metal. lurgical applications, some of which were shown. The advantage of this system is that it is capable of resolving an elementary cube of side (roughly) half a light-wave. Thus in effect a useful magnification of about a thousand is available in three dimensions, and this is of much value in many problems. A simple optical shadow-casting technique was then described and possible applications discussed.

Finally, a review was included of a critical experimental examination intended to test the validity of the method of total reflexion advocated for the exploration of engineering bearing surfaces. In this, a hypotenuse of a right-angled prism is pressed on to the surface and at the points of contact total reflexion is interfered with, revealing thus a dark pattern. Some difficulties in interpretation were discussed.

Dr. Heavens then reviewed the development of recent studies of surface reflectivity and of the assessment of surface films and oxide films on metals. He pointed out that electromagnetic theory enables the optical constants of a material to be deduced from observations on light reflected from a surface. The theory is simple for the ideal theoretical case of a plane boundary separating homogeneous, isotropic regions. Thus accurate experiments can yield information on the nature of a real surface from the difference between such observations and the computations of the theory for the ideal case. In the case of transparent materials, the presence of a transition layer at the surface is revealed by a gradual, rather than abrupt, differential phasechange in the light reflected from the surface. For heavily absorbing materials, the optical constants are easily deduced from polarimetric observations. Since the depth of penetration in these cases is a small fraction of a light-wave, then these observations yield information about the surface layers only and cannot easily be adapted to the problem of examining the bulk properties. Simple criteria exist, however, enabling the homogeneity of the surface layers to be checked.

The problem of examining surface roughness was then discussed by Dr. Heavens. He indicated that this may be tackled by a number of different reflexion methods, according to the scale of the roughness involved. For very rough surfaces (irregularities of many wave-lengths) he described scattering methods as useful. By judicious selection of the wave-length a wide range of roughnesses may be covered. Irregularities of the order of a wave-length may be examined by two-beam interference methods, such as are widely used in the optical industry. Under this heading, the interference microscope, coupled with replica techniques, was mentioned. It was then stressed that for surface roughnesses much smaller 